Article

\title{
The effectiveness of bandwidth knowledge of results on a throwing task in goalball players with visual impairments
}

\author{
Nir Dov Shimony ${ }^{1}$, Ronnie Lidor ${ }^{1}$ and Gal Ziv ${ }^{1, *}$ \\ Received: $2^{\text {nd }}$ February 2020; Accepted: $25^{\text {th }}$ June 2020; Published: $30^{\text {th }}$ September 2020
}

\begin{abstract}
The purpose of the current study was to examine whether a wide bandwidth knowledge of results (WBWKR) would result in better throwing accuracy and consistency compared to a narrow bandwidth knowledge of results (NBWKR) among goalball players with visual impairments. Elite goalball players $(n=14)$ were randomly assigned to one of two groups - a WBWKR or a NBWKR group. The participants practiced a throwing task on a goalball court with either a wide bandwidth $(1.98 \mathrm{~m})$ or a narrow bandwidth $(1.5 \mathrm{~m})$ target. They completed the task at pre-test and acquisition phases. Seventy-two hours after the participants completed the acquisition trials, they performed retention and transfer tests. It was found that in the transfer test, the number of target hits was significantly greater and the absolute error was significantly smaller in the WBWKR participants than in the NBWKR participants. We conclude that goalball players could benefit from the use of WBWKR when practicing throws at the goal.
\end{abstract}

Keywords: Paralympics; blind; motor learning; augmented feedback

\section{Introduction}

In various individual and teams sports, athletes are required to perform an arsenal of motor tasks, among them closed self-paced motor tasks. A closed self-paced motor task has been defined as a motor task that is executed in a stable environment where the circumstances of the act are determined by the performer (Lidor, 2007; Schmidt, Lee, Winstein, Wulf, \& Zelaznik, 2018). In addition, the act is performed when the performer is physically and mentally ready to execute. Examples of closed self-paced motor tasks are shooting free-throw shots in basketball, putting in golf, and throwing darts. In these tasks, performers know in advance, what they are going to do. In order to achieve a high level of proficiency, they can plan their actions to activate task-enhancing instructional techniques. Typically, when performing closed self-paced motor tasks, the performer can see what he or she is doing. That is, vision is used as the dominant sense in the preparation for the act as well as throughout its actual execution (Sigrist, Rauter, Riener, \& Wolf, 2013; Wilson \& Falkel, 2004).

A number of instructional techniques have been found to assist individuals when they perform a closed self-paced motor task. Among these techniques are (a) the implementation of a Quiet Eye (the final fixation or tracking gaze that is directed at a specific location or object in the task space within $3^{\circ}$ of the visual angle or less, for a minimum of $100 \mathrm{msec}$ ) (Harle \& Vickers, 2001); (b) the use of external attentional instructions (the focus is on the intended movement effect) (Wulf, 2013; Wulf \& Su, 2007); and (c) the use of psychological 
(e.g., imagery) and physical (e.g., a ready position) routines implemented prior to the execution of a closed self-paced motor task (Lidor, Hackfort, \& Schack, 2014).

Another instructional technique that was found to improve the performance of a closed self-paced motor task is the provision of feedback (Konttinen, Mononen, Viitasalo, \& Mets, 2004; Schmidt et al., 2018). Feedback - the transmission of evaluative or corrective information about an action, event, or process to the original or controlling source (e.g., the performer), can be classified into two main categories: intrinsic feedback (IF) and augmented feedback (AF) (see Schmidt et al., 2018). IF represents the internal information that is available to the performer from the movement itself, while AF signifies the external information that is provided to the performer in addition to naturally available IF (Lauber \& Keller, 2014). Examples of IF may include seeing the final distance of a thrown object from an intended target, afferent information from the muscles regarding the accuracy of the movements, and proprioceptive understanding of the location of body parts relevant to the motor task at hand. For AF, two main modalities are used: knowledge of performance (KP; augmented feedback related to the nature of the movement produced) and knowledge of results (KR; augmented feedback related to the nature of the result produced in terms of the environmental goal) (Winstein, Pohl, \& Lewthwaite, 1994).

One of the frequently-used forms of KR is bandwidth KR (BWKR) (Lai, Shea, Wulf, \& Wright, 2000). When BWKR is provided, a certain threshold of accuracy around a performance goal is set: if the performance is within this threshold, a qualitative KR is given (e.g., "correct"); however, if the performance falls outside the threshold, a quantitative KR is given (e.g., "missed by $42 \mathrm{~cm}$ ") (Schmidt et al., 2018). Previous studies provided evidence for the effectiveness of BWKR in the development of movement consistency and accuracy (e.g., Lai et al., 2000; Salmoni, Schmidt, \& Walter, 1984), which is mainly achieved by reducing the frequency of feedback (e.g., Sherwood, 1988). This concept can be explained by the guidance hypothesis, where the learner's performance may become dependent on external feedback at the cost of disregarding the available internal sources of information (Salmoni et al., 1984). However, Lee and Carnahan (1990) suggested that the effects of BWKR on performance go beyond the frequency of the feedback. Indeed, in their study, bandwidth conditions were better than frequency yoked conditions at facilitating learning. It was then suggested that BWKR can improve performance by providing error feedback only when corrections are feasible (i.e., error feedback that is not too small for the nervous system to be able to correct), or by providing a larger no-error zone that promotes stabilization of performance, since the learner does not receive error feedback to correct (Lee \& Carnahan, 1990).

A number of studies demonstrated the benefits of the use of BWKR in the learning processes of closed self-paced sporting tasks. For example, Smith, Taylor, and Withers (1997) examined various bandwidth feedback criteria in undergraduate students who practiced a golf-putting task. It was found in this study that a wider bandwidth led to less frequent feedback information and to better golf putting performance in a retention test, compared to a narrow bandwidth. In a study on dart throwing, Coca-Ugrinowitsch et al. (2014) reported a better motor learning effect in a bandwidth group than a control group. In a study on complex gymnastics motor skills (Sadowski, Mastalerz, \& Niznikowski, 2013), it was reported that allowing for a wider bandwidth resulted in better performance in retention tests. Taken together, the findings of the above-mentioned studies provide support for the argument that the use of BWKR, particularly with a wider bandwidth, can result in enhanced accuracy of the learned closed self-paced motor task.

One possible sport environment for testing the effect of BWKR on the learning of closed self-paced motor tasks without the use of visual perception is the game of goalball. Goalball 
is a non-territorial invasion team sport designed exclusively for individuals with visual impairments or blindness, that consists of attack and defense phases (see Morato, Furtado, Gamero, Magalhães, \& Almeida, 2017). The attacking team seeks to score a goal from a restricted space. The defending team attempts to stop the incoming ball by sliding on the floor (Abdolmaleki, Mirzazadeh, Allahyari, \& Ramezani, 2017). During the game, all players must wear eye masks that block any possible vision (Morato et al., 2017), and therefore the players' orientation and spatial skills on the court rely on auditory and tactile feedback (Bednarczuk et al., 2017). It is assumed that augmented feedback information, as an example of an instructional technique, can assist goalball players to improve their throwing accuracy. In a previous field study on six elite-standard Para-Rowing athletes (Schaffert \& Mattes, 2014), athletes with visual impairments benefited from the use of biomechanical analysis via auditory information (i.e. increased mean boat speed). In fact, acoustic feedback was found to be a supportive training aid, as it provided important functional information about the boat motion - independent of vision.

Unfortunately, there is limited evidence-based information on how goalball players can improve processes of motor skill acquisition, such as by practicing throwing a ball at the goal (Morato et al., 2017). In fact, available research on goalball has mainly focused on a small number of game-related aspects, among them (a) the effects of morphological measurements and body composition of goalball players and their relationship to successful performance (Aslan, Karakollukçu, \& Ürgüp, 2018; Romanov, Medovic, Stupar, Jezdimirovic, \& Garunovic, 2017; Scherer, Karasiak, Silva, \& Petroski, 2012); (b) aerobic capacity and physiological attributes of elite goalball players (Goulart-Siqueira et al., 2018; Gulick \& Malone, 2011); (c) dynamic postural stability and balance abilities of goalball players (Aydoğ, Aydoğ, Çakci, \& Doral, 2006); and (d) psychological strategies used by goalball players (Eddy \& Mellalieu, 2003). Additional research is needed to explore how goalball players can improve their skills, particularly their main offensive maneuver - the throw at the goal.

Ball throwing is a critical motor skill in goalball, and a number of variables such as ball velocity, throwing accuracy, and shot techniques were found to affect the probability of scoring a goal (see Lehto, Häyrinen, Laitinen, \& Collet, 2012; Molik et al., 2015; Morato, Menezes, Fonseca, \& Furtado, 2018; Owen, 2014). Acquiring knowledge of the throw outcome depends mainly on the delivery of KR at the completion of the throwing act. Such feedback may allow goalball players to mentally imagine their performance outcome and to make the appropriate corrections in their subsequent throwing attempts. However, during practice coaches may have the tendency to deliver feedback frequently and without the utilization of a bandwidth. This coaching strategy may overwhelm the players' attention, which is already limited to auditory and tactile information. It is possible that much like their visually intact counterparts, goalball players with visual impairments would benefit from the use of BWKR in training.

Therefore, the purpose of our study was to examine the effects of two sizes of bandwidth on accuracy in a goalball throwing task. The effectiveness of BWKR was examined in three phases of learning - acquisition, retention, and transfer. In the acquisition phase, performance was measured (a training effect). In the retention and transfer tests, learning (in our study, a relatively permanent change in the players' accuracy) was assessed. It has been well established in the literature on motor skill acquisition that learners can attain achievements differently in the performance phase (first phase of practice) than in later phases of practice (i.e., retention and transfer) (Soderstrom \& Bjork, 2015). For example, learners can achieve better results in the retention or transfer tests than in the performance phase because they gained some experience with the learned task or instructional technique 
in the early performance phase. It was our assumption that a wider bandwidth would lead to improved throwing accuracy in all phases of the study. In addition, we hypothesized that the players would benefit most from the use of a wide BWKR after gaining some experience with the instructional manipulation, namely in the retention and transfer tests.

\section{Materials and Methods}

\section{Participants}

Elite goalball players ( $n=14$, eight females, six males; mean age $=32.6 \pm 4.07$ years $)$ were recruited to participate in our study. The players had an average of $7.4 \pm 1.9$ years of experience in goalball (range $=5-11$ years). Five of the participants were members of the Israeli women's Paralympic national team, four were Division 1 (the highest division for competitive goalball in Israel) players, and five were Division 2 (the second to the highest division for competitive goalball in Israel) players. All players who were on the Paralympic national team also played in clubs competing at the Divison 1 level. Players in Divison 1 had four to five practice sessions per week, and those who played in Divison 2 practiced between three and four times per week. All players had visual impairments and classified according to the regulations of the International Blind Sports Federation (IBSA): six were classified as B1 - visual acuity less than LogMAR 2.6, three were classified as B2 - visual acuity ranges from LogMAR 1.5 to 2.6 and/or visual field $<10^{\circ}$ in diameter, and five were classified as B3 - visual acuity ranges from LogMAR 1 to 1.4 and/or a visual field $<40^{\circ}$ in diameter) (International Blind Sports Federation, 2018).

The participants, who were naïve to the purpose and assumptions of the study, were randomly assigned to one of two instructional groups: (a) a narrow BWKR group (NBWKR), or (b) a wide BWKR group (WBWKR). The NBWKR group was composed of three national team players, two Division 1 players, and two Division 2 players. The WBWKR group included three national team players, one Division 1 player, and three Division 2 players. The study was approved by the Ethics Committee of the Academic College at Wingate.

\section{The Throwing Task}

A goalball throwing task was performed in four phases - pre-test, acquisition, retention, and transfer. In the phases of pre-test, acquisition, and retention, the participants were asked to throw a standard goalball ball (diameter $=25 \mathrm{~cm}$; mass $=1,250 \mathrm{~g}$ ) towards a target (an aerobic stepper; length $=102 \mathrm{~cm}$, Reebok RE-10152G, Reebok, UK), from a distance of $18 \mathrm{~m}$. The participants' starting position was at the goal line near the left post-bar corner, and their left shoulder was in direct contact with the goalpost. The throwing technique used was a flat shot. The movement of the body during a flat shot is similar to a bowling throw, and has been shown to produce a smooth trajectory of the ball and a higher percentage of goals compared to other throwing techniques (see, for example, Owen, 2014).

In the transfer test, the throwing angle was changed: the target was set at a strategic point between sectors 2 and 3, which represents the area between the center and the rightwinger (line 3 on the goal line). This position required the participant to modify his or her throwing angle to a short diagonal throw. An illustration of the throwing tasks used in the current study is shown in Figure 1. 


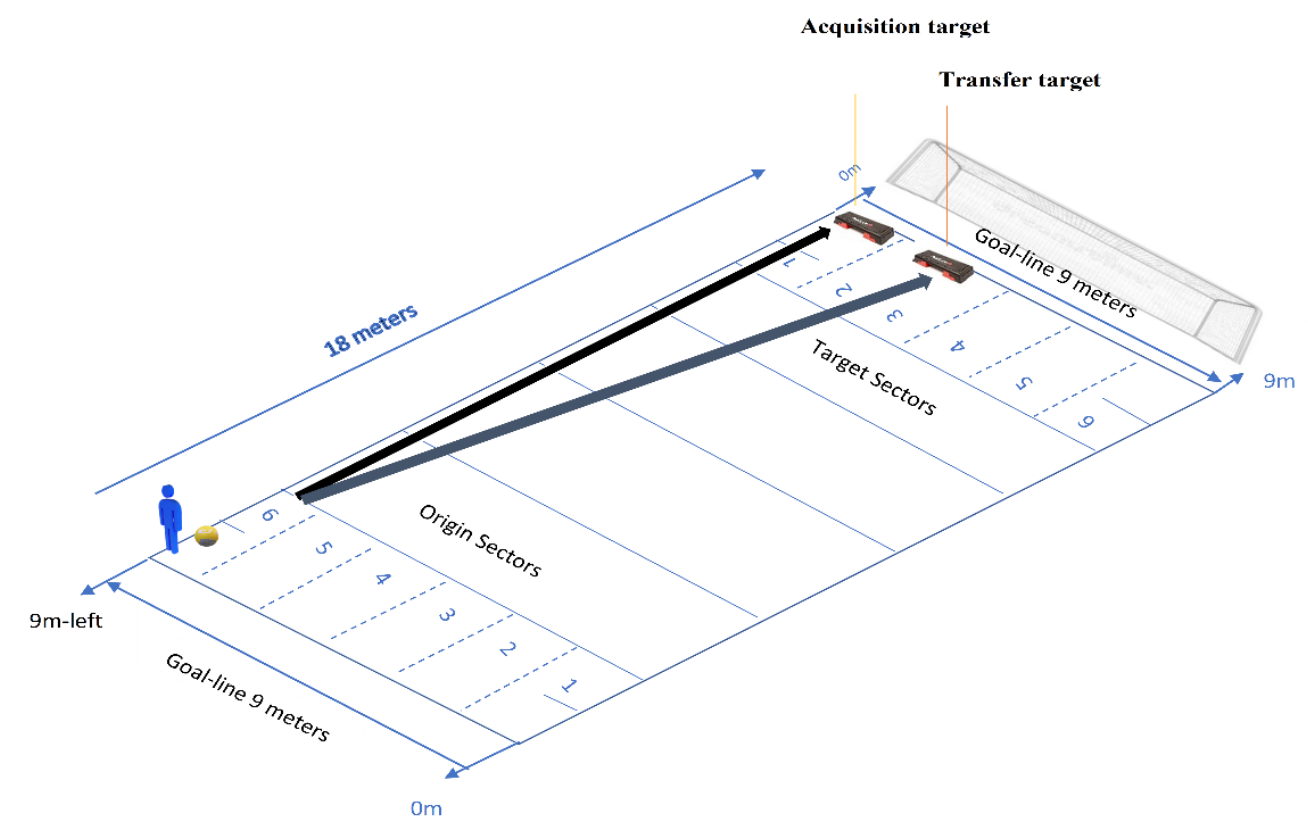

Figure 1. A participant standing at the ready position and performing the acquisition and transfer tasks

\section{Procedure}

The study took place on a standard indoor goalball court. The participants arrived on two occasions, separated by 72 hours. On Day 1, the participants performed the pre-test followed by the acquisition phase. On Day 2, participants performed the retention and transfer tests.

\section{Day 1 - Pre-test and acquisition}

Upon arrival at the indoor goalball court, the participants were provided with a general explanation about the experimental settings and testing procedures. Prior to their participation in the study, one of the researchers (NDS) read the contents of an informed consent form out loud to each participant, who in turn verbally agreed to participate in the study. A visually intact individual who was not part of the research team witnessed this procedure and signed in the name of the participant. This whole process was audiotaped. The participants were then asked to complete a 10-min warm-up session that included jogging, dynamic stretching, and range-of-motion exercises. All participants were instructed to wear their eye mask and remain blindfolded for the duration of the testing.

In the pre-test phase, participants were instructed to perform five throwing trials to the target. Their starting position represented the area where left-winger players receive balls and start game actions, also known as the line of the $9 \mathrm{~m}$ goal line (see Figure 1). A common method to designate origin and target areas on the goalball court was proposed by Morato et al. (2017), which divides the goal-line area into six sectors. Previous studies demonstrated that most throws originate from the right or left of the wingers' area compared to the center (e.g., Molik et al., 2015). The target was positioned on a strategic point (near the right post bar) at which attackers in goalball regularly aim (Morato et al., 2018). Other strategic points represent the distance between the wingers and the left post bar, or the two areas between the center and the wingers (Morato et al., 2017). Another study reported that during women's games the goals were mainly scored in the above-mentioned strategic point areas (Owen, 2014). 
Verbal feedback was given to each player based on each throw outcome: hit or miss. A miss outcome was composed of two parameters - direction (right or left) and distance (in centimeters from the edges of the target). The feedback for throws that missed by over two meters was "over two meters to the left" or "over two meters to the right".

In the acquisition phase, the participants were instructed to perform three blocks of 10 throws each, with a 2-min rest between blocks. Feedback was given based on the groupassigned bandwidth. For the NBWKR group, the bandwidth was $150 \mathrm{~cm}$ (the target $\pm 25 \mathrm{~cm}$ on each side of it), and for the WBWKR group, the bandwidth was $198 \mathrm{~cm}$ (the target \pm 48 $\mathrm{cm}$ on each side). Participants were provided with verbal feedback only if the ball landed outside the assigned bandwidth. The feedback included the distance in centimeters from the edges of the assigned target, and whether the ball landed to the left or right relative to the target. The participants were informed that if feedback was not given their throw was considered a hit.

\section{Day 2 - Retention and transfer}

In the retention test, after completing a 10-minute warm-up, participants were asked to perform one block of 10 throws. The target, the distance from the target, the throw position, and the throw technique were similar to those of the acquisition phase. Verbal feedback given to each player was similar to that given in the pre-test.

The transfer test followed the retention test. Participants remained blindfolded and were provided with an explanation of the new procedure and the location of the new target. The participants were then instructed to perform one block of 10 throws to the new target. Verbal feedback was given to each player in a similar manner to that given in the pre-test.

\section{Dependent Variables}

Two dependent variables were measured: (a) the number of target hits, and (2) absolute error (AE) - the distance in $\mathrm{cm}$ from the edges of the target - a measure of overall accuracy in performance (Schmidt et al., 2018).

\section{Statistical Analyses}

An independent t-test was performed to examine the pre-test skill level of the number of hits and the AE of the participants in the NBWKR and WBWKR groups. A two-way ANCOVA (Group X Block) with repeated measures on the Block factor, and the pre-test number of hits or AE as covariates, was used to assess performance differences in the acquisition phase. A univariate general linear model with the pre-test number of hits or $\mathrm{AE}$ as covariates was used to assess differences in performance in the retention and transfer tests. In addition, a stepwise multiple linear regression was used to examine whether age, experience, and classification of visual ability explain retention and transfer performance. Statistical significance for all analyses was set at $p<.05$, and effect sizes were reported as Cohen's d (> 0.2 small effect; > 0.5 medium effect; > 0.8 large effect, Cohen, 1988) or partial eta squared $\left(\eta^{2}{ }_{p}:>0.1\right.$ small effect; $>0.06$ medium effect; $>0.14$ large effect, Cohen, 1988), according to the statistical analysis used.

\section{Results}

The number of hits and the AE of the NBWKR and WBWKR groups throughout the phases of the study - pre-test, acquisition, retention, and transfer, are presented in Figures 2 and 3 , respectively. 


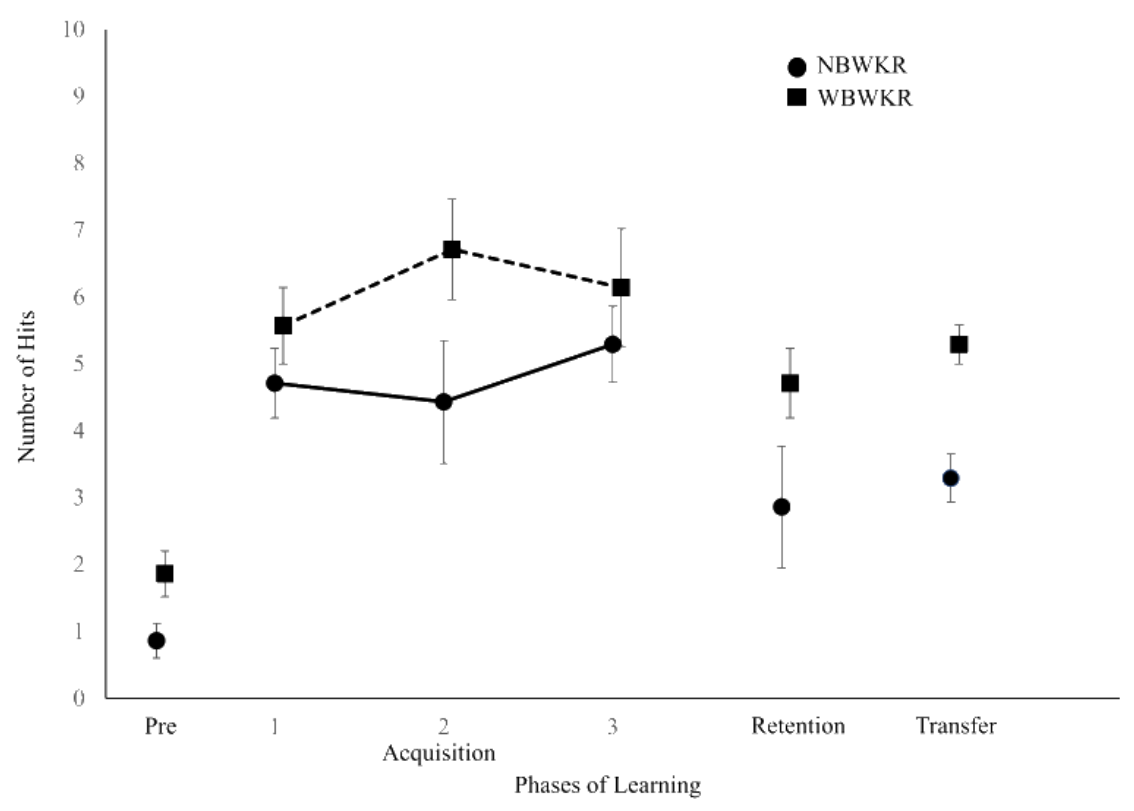

Figure 2. Number of hits throughout the phases of the study (errors bars represent standard error)

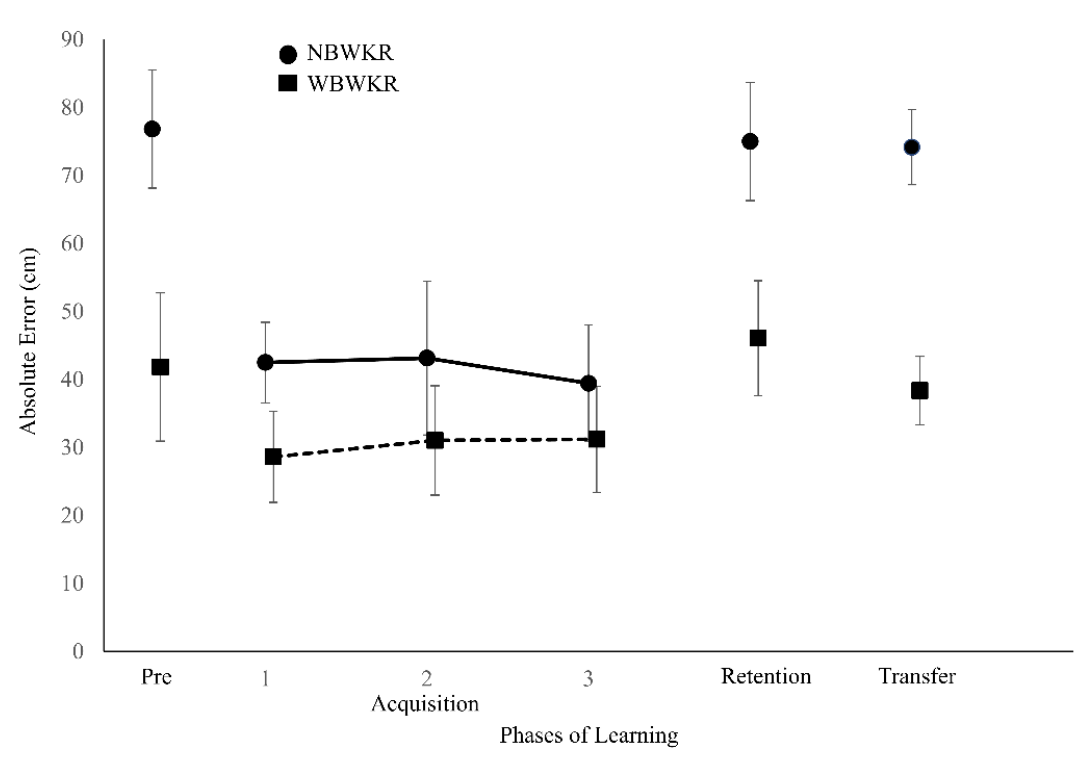

Figure 3. Absolute error throughout the phases of the study (errors bars represent standard error)

\section{Pre-test}

The independent t-test indicated that the difference in performance between the groups was statistically significant, $\mathrm{t}(12)=-2.33, \mathrm{p}<.05$, Cohen's $\mathrm{d}=1.25$. The number of hits was higher in the WBWKR group [1.86 (.90)] compared to the NBWKR group [.86 (.69)]. The independent t-test indicated that the difference in performance between the groups was statistically significant, $\mathrm{t}(12)=2.51, \mathrm{p}<.05$, Cohen's $\mathrm{d}=1.34$. AE was lower in the WBWKR group [41.82 cm (28.84)] compared to the NBWKR group [76.82 cm (22.93)].

\section{Acquisition}

A two-way ANCOVA (Group X Block) with repeated measures on the Block factor and the pre-test number of hits as a covariate failed to find significant differences in the Group factor, $\mathrm{F}(1,11)=.44, \mathrm{p}=.52, \eta^{2} p=.038$, the Block factor, $\mathrm{F}(2,22)=.27, \mathrm{p}=.76, \eta^{2} p=.024$, or the interaction between those factors, $\mathrm{F}(2,22)=.99, \mathrm{p}=.39, \eta^{2} p=.08$. A two-way 
ANCOVA (Group X Block) with repeated measures on the Block factor and the pre-test AE as a covariate failed to find significant differences in the Group factor, $\mathrm{F}(1,11)=.02, \mathrm{p}=.89$, $\eta^{2} p=.002$, the Block factor, $\mathrm{F}(2,22)=.21, \mathrm{p}=.81, \eta^{2} p=.02$, or the interaction between those factors, $\mathrm{F}(2,22)=.03, \mathrm{p}=.87, \eta^{2} p=.002$. In the acquisition phase, the WBWKR group received 15.57 (4.65) feedbacks and the NBWKR group received 11.57 (5.13) feedbacks (51.9\% of trials versus $38.6 \%$ of trials, respectively). This difference was not statistically significant, $\mathrm{t}(12)=1.53, \mathrm{p}=.15$. However, the effect size was large (Cohen's $\mathrm{d}=.82)$.

\section{Retention}

A univariate general linear model with the pre-test number of hits as a covariate indicated that there were no group differences in the number of hits in the retention test, $\mathrm{F}(1,11)=.40, \mathrm{p}=.54, \eta^{2} p=.04$. A univariate general linear model with the pre-test AE as a covariate indicated that there were no group differences in AE during in the retention test, $\mathrm{F}(1,11)=1.22, \mathrm{p}=.29, \eta^{2} p=.10$.

\section{Transfer}

A univariate general linear model with the pre-test number of hits as a covariate indicated a significant difference between groups, $\mathrm{F}(1,11)=10.01, \mathrm{p}=.009, \eta^{2} p=.48$. The WBWKR group [5.18 (.37)] made more hits compared to the NBWKR group [3.39 (.37)]. A univariate general linear model with the pre-test number of hits as a covariate indicated a significant difference between groups, $\mathrm{F}(1,11)=10.27, \mathrm{p}=.008, \eta^{2} p=.48$. The WBWKR group's AE [38.36 cm (13.30)] was lower than that of the NBWKR group [74.16 cm (14.60)].

\section{Analyses of Change from Baseline}

Due to the baseline differences in our data, we also conducted a two-way ANOVA (Group $\mathrm{X}$ Time) with repeated measures on the Time factor (i.e., three blocks of acquisition, retention, and transfer) for the change from baseline of number of hits and AE. The two-way ANOVA indicated a significant main effect for Time, $\mathrm{F}(4,48)=5.29, \mathrm{p}=.001, \eta^{2} p=.31$. A post-hoc analysis using 95\% confidence intervals (CI) revealed that the change in hits from baseline in the retention and transfer tests (2.43 and 2.93, respectively) was lower than the change in hits from baseline in the three acquisition blocks (3.79, 4.21, 4.36, respectively). There was no Group effect, $\mathrm{F}(1,12)=.8, \mathrm{p}=.39, \eta^{2} p=.06$, and no significant interaction, $\mathrm{F}(4,48)=.85, \mathrm{p}=.50, \eta^{2} p=.07$.

The two-way ANOVA indicated a significant main effect for Time, F(4, 48) = 8.41, p < $.001, \eta^{2} p=.41$. A post-hoc analysis using 95\% confidence intervals (CI) indicated that the change in AE from baseline in the retention and transfer tests (1.2 and -3.07, respectively) was higher than the change in $\mathrm{AE}$ from baseline in the three acquisition blocks (-23.78, -22, 24, -24.01, respectively). There was no Group effect, $\mathrm{F}(1,12)=1.59, \mathrm{p}=.23, \eta^{2} p=.12$, and no significant interaction, $\mathrm{F}(4,48)=1.95, \mathrm{p}=.12, \eta^{2} p=.14$. However, since the $\eta^{2} p$ value for the interaction was high, we examined the $95 \%$ confidence intervals (CI) for this interaction as a post-hoc analysis. This analysis indicated that there were no differences between the three blocks of acquisition, the retention test, and the transfer test in the WBWKR group (-13.23, $-10.79,-10.63,4.23,-3.47$, respectively). However, in the NBWKR group, the change in AE from baseline was higher in the retention and transfer tests $(-1.83,-2.67$, respectively) compared to the three blocks of acquisition $(-34.33,-33.69,-37.39$, respectively). That is, the WBWKR participants were able to maintain their performance across the stages of the study, however the NBWKR participants failed to do so in the retention and transfer tests.

\section{Correlations and Multiple Regressions}


Correlations between the classification of visual ability and performance in all phases of the study are presented in Table 1. A stepwise multiple linear regression was used to predict retention and transfer performance, using the following independent variables: age, experience, and classification of visual ability. The results suggested that classification of visual ability and experience predicted $49 \%$ of the variance in the number of hits in the retention test (Adjusted $\mathrm{R} 2=.49, \mathrm{p}=.03)$. The experience variable $(\beta=.66, \mathrm{p}=.01$ ) contributed to the model more than the classification of visual ability variable $(\beta=.52, \mathrm{p}<$ .026). In addition, classification and age predicted $48 \%$ of the variability in $\mathrm{AE}$ in the retention test (Adjusted $\mathrm{R} 2=.48, \mathrm{p}=.01$ ). The experience variable $(\beta=-.58, \mathrm{p}=.01$ ) contributed to the model more than the classification variable $(\beta=.45, \mathrm{p}<.048)$. However, the stepwise multiple regression did not to find any predictors for the number of hits or the $\mathrm{AE}$ in the transfer test.

Table 1. Correlations (r) and statistical significance between the classification of visual ability and performance in all phases of the study

\begin{tabular}{lccc}
\hline Stage & Outcome variable & Classification of visual ability & p-value \\
\hline Pre-test & \# of hits & .30 & .29 \\
& Absolute error & -.10 & .73 \\
Acquisition 1 & \# of hits & .64 & .01 \\
& Absolute error & -.50 & .07 \\
Acquisition 2 & \# of hits & -.54 & .05 \\
& Absolute error & -.63 & .02 \\
Acquisition 3 & \# of hits & .29 & .31 \\
& Absolute error & -.25 & .39 \\
Retention & \# of hits & .38 & .17 \\
& Absolute error & -.30 & .30 \\
Transfer & \# of hits & .46 & .10 \\
& Absolute error & -.29 & .32 \\
\hline
\end{tabular}

\section{Discussion}

The purpose of the current field study was to examine the effectiveness of a BWKR on the performance and learning of a closed self-paced motor task - a throw in goalball. We hypothesized that compared to a narrow bandwidth, a wide bandwidth would result in better throwing accuracy in the task acquisition as well as in the delayed retention and transfer tests. In addition, we assumed that performance would be more accurate in the retention and transfer tests compared to the acquisition phase. The findings obtained in our study did not show that the WBWKR participants improved accuracy ability in the acquisition phase or in the retention test, however they outperformed the NBWKR participants in the transfer test (i.e., a significantly greater number of target hits and smaller AE values). In addition, although the two-way ANOVA of AE change from baseline did not lead to statistically significant findings, a large interaction effect size was found. An analysis of the 95\% CI of this interaction showed that although the participants in the WBWKR group maintained their $\mathrm{AE}$ values throughout the acquisition, retention, and transfer stages, the $\mathrm{AE}$ of the participants in the NBWKR deteriorated from the three acquisition blocks to the retention and transfer tests.

We used two common approaches in our data analysis, due to the baseline differences between groups in both $\mathrm{AE}$ and number of hits. These two approaches are: (a) an analysis of covariance (ANCOVA) with baseline values as the covariate, and (2) an ANOVA with the calculated changes from baseline rather than the absolute values of the variables (Van Breukelen, 2006). These approaches can lead to contradictory conclusions - a phenomenon termed "Lord's paradox" (Lord, 1967; Senn, 2006). However, more confidence in the results can be obtained when both approaches reach similar conclusions (Van Breukelen, 2013). 
Indeed, in the current study, in both approaches the participants in the WBWKR group outperformed the participants in the NBWKR group.

Similar findings to the ones found in our study were observed in previous studies on the effectiveness of BWKR in learning a closed self-paced motor task. For example, Cruz and colleagues (2018), who examined the effect of bandwidth and no-KR conditions on shortand long-term learning of motor skills, found complementary group performance in shortterm retention tests, whereas the bandwidth groups outperformed the control group in transfer tests. Schiffman, Luchies, Richards, and Zebas (2002), who investigated force control abilities in young and older adults under different feedback conditions, reported a similar training effect of bandwidth performance during acquisition. Additionally, Sherwood (1988) observed increased movement consistency during practice in all tested bandwidth groups compared to a control group.

According to the instability hypothesis, reduced AF in early phases of skill acquisition increases practice stability and promotes performers to produce similar movement patterns (Sherwood, 1988). Furthermore, once the movement becomes stable in the acquisition (early practice) phase, the effect of consistent movement response can be retrieved in advanced phases of learning - the retention and transfer phases (Lai \& Shea, 1999). The performance observed in the acquisition phase in our study is somewhat aligned with the latter principle, as both bandwidth groups showed satisfactory responses in the early phases of acquisition. In addition, the stability response effect was present in the transfer test in the WBWKR participants. Yet, since a control group (KR in all trials) was not included in our study, it was difficult to accurately interpret the exact mechanism that led to the bandwidth groups' performance in the acquisition phase or in the retention test.

Learning effects are typically observed in retention and transfer tests rather than during acquisition (Lee \& Maraj, 1994; Salmoni et al., 1984). Indeed, Schmidt and Bjork (1992) suggested that performance during acquisition is not a valid indicator of learning. Unfortunately, coaches and instructors may often be misled by short-term performance outcomes, which may cause them to ignore other potential long-term effects of practice (Wulf, Shea, \& Lewthwaite, 2010; Soderstrom \& Bjork, 2015). From a psychophysical perspective, Brashers-Krug and colleagues (1996) provided motor memory evidence of synaptic consolidation processes that continue to evolve after training has ceased.

One possible explanation for the lack of significant differences in the retention test in our study may be related to the short training program, compared to other related studies. For example, Smith et al. (1997) conducted a training session that consisted of 50 acquisition trials. In another study, Shewokis, Kennedy, and Marsh (2000) examined the effectiveness of BWKR on learning of an isokinetic strength task, in which participants performed 90 acquisition trials over three training days. Badets and Blandin (2005) reported similar findings in an observational study which implemented a training session of 72 acquisition trials. Therefore, it is possible that lengthening the acquisition phase could have elicited more pronounced performance differences between the bandwidth groups in the retention test.

The learning effect of the wide bandwidth in the transfer test can be partially supported by the relative frequency hypothesis, which implies that wider bandwidth conditions prevent maladaptive short-term movement corrections in performance (Sherwood, 1988). In contrast, high-frequency AF may cause performers to change their motor behavior in an inconsistent manner, thereby eliciting instability in practice and a decline in performance (Salmoni et al., 1984). In our study, the bandwidth manipulation caused an overall reduction in the AF delivered for both groups, and was shown to promote similar performance in the subsequent practice blocks and retention. 
Only learning, and not performance, was significantly affected by the bandwidth size manipulation in our study. Therefore, aligned with the relative frequency hypothesis is the notion of players developing movement consistency and adapting repeatable motor behavior due to successful and unchangeable performance. However, one may expect that wider bandwidth conditions will result in enhanced short-term motor performance, and also facilitate long-term learning. This was not the case in our study.

Sadowski and colleagues (2013) determined the criterion of movement accuracy in a learning course of a complex gymnastic sequence. Similar to our study, when performance fell within an acceptable range, quantitative KR was withheld - leading to internal interpretation of a correct achievement. This interpretation was shown to promote similar motor behavior in the trials that followed (Lee \& Carnahan, 1990). Furthermore, Lee and Maraj (1994) postulated that in wide bandwidth conditions, the performers experienced a suitable training environment that was more sensitive to their needs. Thus, our assumption was that in both BWKR groups the acceptable range of errors practiced in acquisition caused an equal reduction in the feedback delivered, and essentially provided an adequate guiding effect in the retention and transfer tests.

The guidance hypothesis attempts to explain the reasoning behind the relative feedback theory, namely that high relative feedback frequency, present to a greater extent in narrow bandwidth than in wide bandwidth conditions, causes individuals to become reliant upon the $\mathrm{AF}$ delivered in the retention and transfer tests (Salmoni et al., 1984). Moreover, frequent $\mathrm{AF}$ impedes the performer from using IF mechanisms, due to the large amount of external augmented information. Wright et al. (1997) and Shewokis et al. (2000) demonstrated that BWKR groups made fewer alterations in performance, regardless of whether quantitative or qualitative feedback was provided to them. Fewer changes in motor behavior may result in increased consistency, enhanced motor learning, and reduced reliance on AF information (Lee \& Carnahan, 1990). In line with the guidance hypothesis, the decreased amounts of guidance received in the acquisition phase, combined with wider bandwidth conditions, may have led to the improved transfer performances in our study. However, as noted previously, solely the presentation of feedback during acquisition cannot fully explain the results obtained in the current study, as the underlying mechanism of the bandwidth feedback is not readily available.

Our aim in the current investigation was not only to add to the literature on the effectiveness of bandwidth manipulations when individuals attempt to learn a closed selfpaced motor task, but also to examine the responsiveness of athletes with visual impairments to a feedback strategy that has been shown to improve performance and learning in athletes without visual impairments (e.g., gymnasts) (Sadowski et al., 2013). In the game of goalball, afferent sensory information from visual input is blocked (Molik et al., 2015), and therefore the players' ability to perceive the game's environment is mainly based on auditory and tactile information (see Çolak, Bamaç, Aydin, Meriç, \& Özbek, 2004). Augmented feedback, as an instructional technique, can be implemented by players to strengthen the use of the auditory channel of communication.

In fact, from a communication point of view, the provision of feedback is an integral part of goalball (Abdolmaleki et al., 2017) - throughout the game, verbal communication (e.g., AF) occurs at multiple levels. For example, feedback information that is shared among the players allows them to safely maneuver around the court. In addition, during a game, coaches and players seek to communicate and provide feedback to each other to effectively work together on the desired objective - scoring a goal. Therefore, it is argued that due to the nature of the game of goalball, players are already exposed to a high amount of AF information, in both practice sessions and games. In this respect, WBWKR is proposed to 
provide goalball coaches and players with an alternative instructional tool that has the potential to reduce the available external information, as well as to trigger performers to attend to their own internal feedback learning processes.

In goalball, players' participation requires adherence to classification rules that ensure equality. These rules regulate the eligibility of a player or a group of players to compete (see Molik et al., 2015). According to Molik et al. (2015), goalball players classified as B2 or B3 were found to be more effective in the offensive phase of the game. Their observations are in line with the findings that emerged from our study, in which classification and age factors were shown to predict variability in performance in the retention test. A positive correlation trend was found in those players who exhibited better visual abilities and demonstrated a greater number of target hits. The relationships between the age factor and performance that were found for the retention test revealed a similar trend. These findings can be useful for those professionals - instructors, coaches, and physical education teachers - who teach motor skills in goalball. For example, these professionals can teach players classified as B2 or B3 specific throwing skills, such as increasing accuracy in throws to weaker points on the opposite side.

Two limitations of the current study are noteworthy. First, the small sample size prevented us from reaching robust results. Unfortunately, when studying goalball players, it is difficult to reach the required number of participants in order to achieve a high statistical power, as the population of these athletes is small. Our sample, however, included goalball players of the highest level. Second, the differences between groups at baseline make it difficult to provide a causal relationship between the size of the bandwidth and performance. Still, as mentioned previously, we used two accepted approaches for dealing with such differences: (a) an ANCOVA with the baseline values as the covariate, and (b) an ANOVA with the change from baseline as the dependent variable. Due to the small sample size, we also looked beyond statistical significance, and when effect sizes were large, we examined 95\% confidence intervals to gain more insight from the data. Both approaches led to a similar conclusion: the participants in the WBWKR group outperformed the participants in the NBWKR group, therefore strengthening our assumption that a wider bandwidth facilitates improvements in performance.

However, caution is still warranted when interpreting the findings that emerged from our study. Taking into account (a) the small sample of goalball players that participated in this study ( $\mathrm{N}=14)$, (b) the lack of a control group (e.g., a 100\% KR group) due to the small number of participants, and (c) the small number of practice trials administered to the players, additional studies should further examine manipulations of BWKR provision in goalball training programs.

\section{Practical Implications}

Based on the findings in our field study, we propose three instructional steps that can be applied in the process of learning to throw in goalball:

(a) WBWKR should be used as an instructional technique in preference over NBWKR;

(b) The content of WBWKR should match the needs of each player according to his or her classification, age, and number of years playing the game;

(c) Achievements of goalball players in early phases of practice (i.e., acquisition) can differ from those in advanced phases (i.e., retention and transfer). Coaches, instructors, and physical educators should be aware of these differences, and therefore select those instructional techniques (e.g., WBWKR) that have the potential to facilitate learning in the advanced phases. 


\section{Perspectives}

The game of goalball has been included in the Paralympic Games since 1976. Goalball enables athletes who are visually impaired or blind to participate in a competitive team game activity (Haegele, 2018) that requires a high level of proficiency in throwing a ball at a designated goal. In order to design training sessions aimed at improving the accuracy and speed of ball-throwing in goalball, coaches who teach players how to throw at the goal should adopt an evidence-based approach. The synthetization of evidence-based knowledge into goalball training programs should improve the quality of the programs, as well as assist the individual player and the team to improve their game ability.

The findings that emerged from the current field study can be implemented by goalball coaches when giving instructions to their players and when providing them with augmented feedback information. More specifically, the use of WBWKR can help goalball players not only to improve their accuracy of performance, but also to use self-feedback mechanisms when the performance is within the bandwidth and no augmented feedback is given. That is, the provision of WBWKR can combine instructions imposed by the coach with learning strategies developed and used by the athlete.

\footnotetext{
Author affiliations:

1 Motor Behavior Laboratory, The Academic College at Wingate, Netanya, Israel; nirshimony@gmail.com. lidor@wincol.ac.il.galziv@yahoo.com

* Correspondence: galziv@yahoo.com; Tel.: +972-9-863-9265
}

Author Contributions: Conceptualization, N.D.S., R.L. and G.Z.; Methodology, N.D.S. and G.Z.; Formal Analysis, G.Z.; Writing-Original Draft Preparation, N.D.S.; Writing-Review \& Editing, G.Z. and R.L.

Funding: This research received no external funding

Conflicts of Interest: The authors declare no conflict of interest.

\section{References}

Abdolmaleki, H., Mirzazadeh, Z., Allahyari, M., \& Ramezani, M. (2017). Identify and analysis of performance evaluation indicators of Iranian goalball coaches. Annals of Applied Sport Science, 3, 43-56. https://doi.org/10.18869/acadpub.aassjournal.3.3.43

Aslan, C. S. , Karakollukçu, M., \& Ürgüp, S. (2018). Effects of body composition on achievement in goalball. Journal of Physical Fitness, Medicine \& Treatment in Sport, 3(1). https://doi.org/10.19080/JPFMTS.2018.03.555603

Aydoğ, E., Aydoğ, S. T., Çakci, A., \& Doral, M. N. (2006). Dynamic postural stability in blind athletes using the Biodex Stability System. International Journal of Sports Medicine, 27, 415-418. https://doi.org/10.1055/s-2005-865777

Badets, A., \& Blandin, Y. (2005). Observational learning: Effects of bandwidth knowledge of results. Journal of Motor Behavior, 37, 211-216. https://doi.org/10.3200/JMBR.37.3.211-216

Bednarczuk, G., Molik, B., Morgulec-Adamowicz, N., Kosmol, A., Wiszomirska, I., Rutkowska, I., \& Perkowski, K. (2017). Static balance of visually impaired paralympic goalball players. International Journal of Sports Science and Coaching, 12, 611-617. https://doi.org/10.1177/1747954117727791

Brashers-Krug, T., Shadmehr, R., \& Bizzi, E. (1996). Consolidation in human motor memory. Nature, 382, 252-255. https://doi.org/10.1038/382252ao

Coca-Ugrinowitsch, A. A., Benda, R. N., Aburachid, L. M., De Andrade, A. G. P., Greco, P. J., Menzel, H. J. K., \& Ugrinowitsch, H. (2014). Bandwidth knowledge of results on the learning of the saloon dart throwing task. Perceptual and Motor Skills, 118, 462-474. https://doi.org/10.2466/25.23.PMS.118k17w9

Cohen, J. (1988). Statistical power analysis for the behavioral sciences. ( $2^{\text {nd }}$ ed.). Lawrence Erlbaum Associates.

Çolak, T., Bamaç, B., Aydin, M., Meriç, B., \& Özbek, A. (2004). Physical fitness levels of blind and visually impaired goalball team players. Isokinetics and Exercise Science, 12, 247-252. https://doi.org/10.3233/IES-2004-0182 
Cruz, M. P., Benda, R. N., Carvalho, M. F. S. P., Lage, G. M., Cattuzzo, M. T., \& Ugrinowitsch, H. (2018). Bandwidth knowledge of results persists on motor skills acquisition. Motricidade, 14, 107-114. https://doi.org/10.6063/motricidade.14294

Eddy, K. A., \& Mellalieu, S. D. (2003). Mental imagery in athletes with visual impairments. Adapted Physical Activity Quarterly, 20, 347-368. https://doi.org/10.1123/apaq.20.4.347

Goulart-Siqueira, G., Ben, S., Ferreira, A. R. P., Zagatto, A. M., Foster, C., \& Boullosa, D. (2018). Relationships between different field test performance measures in elite goalball players. Sports, 7(1), 6. https://doi.org/10.3390/sports7010006

Gulick, D. T., \& Malone, L. A. (2011). Field test for measuring aerobic capacity in paralympic goalball athletes. International Journal of Athletic Therapy \& Training, 16, 22-25. https://doi.org/10.1123/ijatt.16.5.22

Haegele, J.A. (2018). Youth leisure-time physical activity from the perspectives of youth adults with visual impairments. European Journal of Adapted Physical Activity, 11, 10. https://doi.org/10.5507/euj.2018.010

Harle, S. K., \& Vickers, J. N. (2001). Training quiet eye improves accuracy in the basketball free throw. Sport Psychologist, 15, 289-305. https://doi.org/10.1123/tsp.15.3.289

International Blind Sports Federation. (2018). IBSA classification rules - December 2018 [PDF file]. https://www.ibsasport.org/documents/files/182-1-IBSA-Classificationrules-2018.pdf

Konttinen, N., Mononen, K., Viitasalo, J., \& Mets, T. (2004). The effects of augmented auditory feedback on psychomotor skill learning in precision shooting. Journal of Sport and Exercise Psychology, 26, 306-316. https://doi.org/10.1123/jsep.26.2.306

Lai, Q., \& Shea, C. H. (1999). Bandwidth knowledge of results enhances generalized motor program learning. Research Quarterly for Exercise and Sport, 70, 79-83. https://doi.org/10.1080/02701367.1999.10607734

Lai, Q., Shea, C. H., Wulf, G., \& Wright, D. L. (2000). Optimizing generalized motor program and parameter learning. Research Quarterly for Exercise and Sport, 71, 1024. https://doi.org/10.1080/02701367.2000.10608876

Lauber, B., \& Keller, M. (2014). Improving motor performance: Selected aspects of augmented feedback in exercise and health. European Journal of Sport Science, 14, 36-43. https://doi.org/10.1080/17461391.2012.725104

Lee, T. D., \& Carnahan, H. (1990). Bandwidth knowledge of results and motor learning: More than just a relative frequency effect. The Quarterly Journal of Experimental Psychology Section A, 42, 777-789. https://doi.org/10.1080/14640749008401249

Lee, T. D., \& Maraj, B. K. V. (1994). Effects of bandwidth goals and bandwidth knowledge of results on motor learning. Research Quarterly for Exercise and Sport, 65, 244-249. https://doi.org/10.1080/02701367.1994.10607625

Lehto, H., Häyrinen, M., Laitinen, T., \& Collet, K. (2012). Match analysis and a comparison between winning and losing teams in men's elite level goalball. In World Congress of Performance Analysis of Sport IX Programme \& e-Book of Abstracts.

Lidor, R. (2007). Preparatory routines in self-paced events. In G. Tenenbaum \& R. C. Eklund (Eds.), Handbook of sport psychology (pp. 445-465). Hoboken, NJ: John Wiley \& Sons.

Lidor, R., Hackfort, D., \& Schack, T. (2014). Performance routines in sport - meaning and practice. In A. Papaioannou \& D. Hackfort (Eds.), Routledge companion to sport and exercise psychology (pp. 480-494). London, UK: Routledge.

Lord, F. M. (1967). A paradox in the interpretation of group comparisons. Psychological Bulletin, 68, 304. https://doi.org/10.1037/ho025105

Molik, B., Morgulec-Adamowicz, N., Kosmol, A., Perkowski, K., Bednarczuk, G., Skowronski, W., ... Szyman, R. J. (2015). Game performance evaluation in male goalball players. Journal of Human Kinetics, 48, 43-51. https://doi.org/10.1515/hukin-2015-0090

Morato, M. P., Furtado, O. L. P. D. C., Gamero, D. H., Magalhães, T. P., \& Almeida, J. J. G. D. (2017). Development and evaluation of an observational system for goalball match analysis. Revista Brasileira de Ciências Do Esporte, 39, 398-407. https://doi.org/10.1016/j.rbce.2016.08.002 
Morato, M. P., Menezes, R. P., Fonseca, S., \& Furtado, O. L. P. D. C. (2018). Faster balls increase the probability of scoring a goal in female and male elite goalball. Revista Brasileira de Ciencias Do Esporte, 40, 427-434. https://doi.org/10.1016/j.rbce.2018.03.027

Owen, G. (2014). Exploratory analysis of goalball : A regression based approach (Unpublished master's thesis). University of Chester, Chester, UK.

Romanov, R., Medovic, B., Stupar, D., Jezdimirovic, T., \& Garunovic, B. (2017). The connection between certain morphological parameters and results in goalball players. International Journal of Morphology, 35,1396-1402. https://doi.org/10.4067/So71795022017000401396

Sadowski, J., Mastalerz, A., \& Niznikowski, T. (2013). Benefits of bandwidth feedback in learning a complex gymnastic skill. Journal of Human Kinetics, 37, 183-193. https://doi.org/10.2478/hukin-2013-0039

Salmoni, A. W., Schmidt, R. A., \& Walter, C. B. (1984). Knowledge of results and motor learning : A review and critical reappraisal. Psychological Bulletin, 95, 355-386. https://doi.org/10.1037/0033-2909.95.3.355

Schaffert, N., \& Mattes, K. (2014). Effects of acoustic feedback training in elite-standard Para-Rowing. Journal of Sports Sciences, 33, 411-418. https://doi.org/10.1080/02640414.2014.946438

Scherer, R. L., Karasiak, F. C., Silva, S. G., \& Petroski, E. L. (2012). Morphological profile of goalball athletes. European Journal of Human Movement, 28, 1-13. https://www.eurjhm.com/index.php/eurjhm/article/view/276

Schiffman, J. M., Luchies, C. W., Richards, L. G., \& Zebas, C. J. (2002). The effects of age and feedback on isometric knee extensor force control abilities. Clinical Biomechanics, 17, 486-493. https://doi.org/10.1016/So268-0033(02)oo041-4

Schmidt, R. A., \& Bjork, R. A. (1992). New conceptualizations of practice: Common principles in three paradigms suggest new concepts for training. Psychological Science, 3, 207-217. https://doi.org/10.1111/j.1467-9280.1992.tboo029.x

Schmidt, R. A., Lee, T. D., Winstein, C., Wulf, G., \& Zelaznik, H. N. (2018). Motor control and learning: A behavioral emphasis. Champaign, IL: Human Kinetics.

Senn, S. (2006). Change from baseline and analysis of covariance revisited. Statistics in Medicine, 25, 4334-4344. https://doi.org/10.1002/sim.2682

Sherwood, D. E. (1988). Effect of bandwidth knowledge of results on movement consistency. Perceptual and Motor Skills, 66, 535-542. https://doi.org/10.2466/pms.1988.66.2.535

Shewokis, P. A., Kennedy, C. Z., \& Marsh, J. L. (2000). Effects of bandwidth knowledge of results on the performance and learning of a shoulder internal rotation isokinetic strength task. Isokinetics and Exercise Science, 8, 129-139. https://doi.org/10.3233/IES-2000-0043

Sigrist, R., Rauter, G., Riener, R., \& Wolf, P. (2013). Augmented visual, auditory, haptic, and multimodal feedback in motor learning: A review. Psychonomic Bulletin and Review, 2O, 21-53. https://doi.org/10.3758/s13423-012-0333-8

Smith, P. J., Taylor, S. J., \& Withers, K. (1997). Applying bandwidth feedback scheduling to a golf shot. Research Quarterly for Exercise and Sport, 68, 215-221. https://doi.org/10.1080/02701367.1997.10608000

Soderstrom, N. C., \& Bjork, R. A. (2015). Learning versus performance: An integrative review. Perspectives on Psychological Science, 10, 176-199. https://doi.org/10.1177/1745691615569000

van Breukelen, G. J. (2006). ANCOVA versus change from baseline had more power in randomized studies and more bias in nonrandomized studies. Journal of Clinical Epidemiology, 59, 920-925. https://doi.org/

van Breukelen, G. J. (2013). ANCOVA versus CHANGE from baseline in nonrandomized studies: The difference. Multivariate Behavioral Research, 48, 895-922. https://doi.org/10.1016/j.jclinepi.2006.02.007

Wilson, T. A., \& Falkel, J. (2004). SportsVision - Training for better performance. Champaign, IL: Human Kinetics. 
Winstein, C. J., Pohl, P. S., \& Lewthwaite, R. (1994). Effects of physical guidance and knowledge of results on motor learning: Support for the guidance hypothesis. Research Quarterly for Exercise and Sport, 65, 316-323. https://doi.org/10.1080/02701367.1994.10607635

Wright, D. L., Smith-Munyon, V., \& Sidaway, B. (1997). How close is too close for precise knowledge of results. Research Quarterly for Exercise and Sport, 68, 172-176. https://doi.org/10.1080/02701367.1997.10607994

Wulf, G. (2013). Attentional focus and motor learning: A review of 15 years. International Review of Sport and Exercise Psychology, 6, 77-104. https://doi.org/10.1080/1750984X.2012.723728

Wulf, G., Shea, C., \& Lewthwaite, R. (2010). Motor skill learning and performance: A review of influential factors. Medical Education, 44, 75-84. https://doi.org/10.1111/j.1365-2923.2009.03421.x

Wulf, G., \& Su, J. (2007). An external focus of attention enhances golf shot accuracy in beginners and experts. Research Quarterly for Exercise and Sport, 78, 384-389. https://doi.org/10.1080/02701367.2007.10599436 under the terms and conditions of the Creative Commons Attribution (CC BY) license (http://creativecommons.org/licenses/by/4.0/). 